\title{
The anti-metastatic effect of baicalein on colorectal cancer
}

\author{
YUXIA CHAI, JIZHONG XU and BAOJUN YAN \\ The First Affiliated Hospital of Zhengzhou University, Zhengzhou, Henan 450052, P.R. China
}

Received July 15, 2016; Accepted December 14, 2016

DOI: $10.3892 / o r .2017 .5437$

\begin{abstract}
Baicalein, a naturally occurring flavonoid isolated from the roots of Scutellaria baicalensis, is historically and widely used as anti-inflammatory and anticancer therapy. Nevertheless, the anti-metastatic effect and underlying molecular mechanisms of baicalein on colorectal carcinoma (CRC) remain unclear. The aim of the present study was, therefore, to invastigate the anti-metastatic activity of baicalein and related mechanism(s) on CRC cells. In this study, we observed that baicalein treatment inhibited proliferation, as well as migration and invasion of HT-29 and DLD1 cells. Baicalein decreased the expression of the matrix metalloproteinases-2 (MMP-2) and MMP-9 in a dose-dependent manner. Also, baicalein treatment significantly reduced phosphorylation of extracellular signal regulated kinases (ERK). Furthermore, in DLD1 cells, MEK1 overexpression partially blocked the anti-metastatic effects of baicalein. Combined treatment with an ERK inhibitor (U0126) and baicalein led to the synergistic reduction of MMP-2/9 expression; and the invasive capabilities of DLD1 cells were also inhibited markedy. Finally, intragastric administration of baicalein inhibited CRC xenograft growth in vivo and suppressed the phosphorylation of ERK and the expression of MMP-2/9 in tumor tissues. Consequently, baicalein suppresses CRC cell invasion via inhibition of the ERK signaling pathways, indicating that baicalein is a potential agent for CRC treatment.
\end{abstract}

\section{Introduction}

CRC is one of the leading causes of death worldwide (1). Aggressive local invasion and metastasis make CRC difficult to treat (2). Therefore clarifying the mechanism of invasion of CRC to find new treatment targets is urgent.

Metastasis of cancer cells is a complex processes during which the degradation of the extracellular matrix (ECM) plays an important role (3). MMP-2/-9 play important roles in

Correspondence to: Professor Yuxia Chai, The First Affiliated Hospital of Zhengzhou University, No. 1 East Jiangshe Road, Zhengzhou, Henan 450052, P.R. China

E-mail: 15515887779@163.com

Key words: colorectal cancer, baicalein, invasion and migration, MMP, ERK degrading ECM and its involvement is complex in the process of cancer metastasis $(3,4)$. Overactivity of ERK signaling pathway has been found in almost half of known human tumor cell lines and in many human primary tumors derived from different origins (5). ERK signaling pathway plays a vital role in the synthesis of MMP-2/-9 $(3,6)$. Overactivity of ERK pathway is observed in CRC $(7,8)$ and is correlated with the metastasis of CRC $(9,10)$.

Baicalein is extracted from the roots of Scutellaria baicalensis or Scutellaria radix. The chemical structure of baicalein is shown in Fig. 1A. The antitumor biological effect of baicalein has been found in many tumors (11-13). Baicalein has been found to possess antitumor effect in hepatocellular carcinoma, glioma and bladder cancer $(3,14-16)$, but the antimetastatic effect and related mechanism(s) in CRC are still unclear. Thus, the present study investigated the effects of baicalein in CRC invasion and metastasis and related mechanisms.

\section{Materials and methods}

Cell lines and reagents. CRC HT29 and DLD1 cell lines were purchased from the American Type Culture Collection (ATCC; Manassas, VA, USA) and cultured in RPMI-1640 (HyClone Laboratories, Inc., Logan, UT, USA) medium with $10 \%$ fetal bovine serum (FBS; HyClone Laboratories). The cells were cultured at $37^{\circ} \mathrm{C}$ with $5 \% \mathrm{CO}_{2}$. Anti-MMP-2, ERK, MMP-9 and p-ERK were purchased from Cell Signaling Technology (Beverly, MA, USA). Unless otherwise indicated, all the other chemicals were purchased from Sigma-Aldrich (St. Louis, MO, USA).

Apoptosis assays. Apoptotic and/or necrotic cells were analysed by propidium iodide (PI) uptake using Annexin V binding an Annexin V-FITC/PI kit as previously described (15). Briefly, CRC cells were seeded into 6-well plates at a density of $1 \times 10^{5}$ cells/well for $12 \mathrm{~h}$ and treated with $0,40,60$ and $80 \mu \mathrm{M}$ of baicalein for $48 \mathrm{~h}$. After washing with cold phosphate-buffered saline (PBS), cells were resuspended in Annexin $\mathrm{V}$ binding buffer. Cells were incubated in Annexin V-FITC for $15 \mathrm{~min}$, washed and then incubated with PI. Samples were detected by flow cytometer with CellQuest software.

Cell growth assay and focus formation assay. Cell growth rate was detected using the MTT assay. Briefly, cells were seeded in a 96-well plate at a density of $1.5 \times 10^{3}$ cells. Cells were treated 
with baicalein $(0,10,20,30,40,50,60,80,100$ and $120 \mu \mathrm{M})$ (R\&D Systems, Inc., Minneapolis, MN, USA) for $24 \mathrm{~h}$. MTT assay was done in accordance with the manufacturer's instructions. Each experiment was done in triplicate and data were expressed as mean \pm SD. In focus formation assay, 100 cells were firstly seeded onto a plate and then cultured with $(0,40$, 60 and $80 \mu \mathrm{M}$ ) baicalein for 2 weeks. The plates were fixed and then stained with $1 \%$ crystal violet. All experiments were performed in triplicate.

Construction of expression plasmids and transfection. The construction of the expression plasmids and their transfection was performed in accordance with the manufacturer's instructions (3). First, the full-length pcDNA3.1 (Invitrogen, Carlsbad, CA, USA) MEK1 vector was made by cloning the full-length PCR product of MEK1 with $\mathrm{KOD}^{\circledR}$ DNA polymerase (Toyobo Co., Ltd., Osaka, Japan). Then we measured the plasmid sequences to confirm the sequences of the plasmid. In transient transfection experiments, cells were plated at a density of $2 \times 10^{5}$ cells/well in a 6-well plate, $24 \mathrm{~h}$ later they were transfected with $4.0 \mu \mathrm{g}$ pcDNA3.1(+)-MEK1 vector via Lipofectamine 2000 (Invitrogen) in accordance with the manufacturer's protocol. The $4.0 \mu \mathrm{g}$ pcDNA3.1(+) empty vector was used as a negative control.

Cell invasion and migration assay. The migration and invasion ability of cells were detected by Transwell assays. Migration and invasion assay was performed with 24-well Transwell chambers coated with Matrigel or not (Becton-Dicknson, Billerica, MA, USA) as previously described. For the migration assay, cells were seeded into inner well and cultured in medium with $0,10,20$ and $30 \mu \mathrm{M}$ baicalein. After $16 \mathrm{~h}$, cells on the bottom side of the inner well were fixed in alcohol, fixed in crystal violet and counted. Invasion assay was performed with 24-well Transwell chamber coated with Matrigel as previously described (3).

Western blotting assay. After treated with U0126 or baicalein, $2 \times 10^{6}$ cells were added into $200 \mu \mathrm{l}$ of lysis buffer (Fermentas, Waltham, MA, USA). By 10\% SDS-polyacrylamide gel electrophoresis, the proteins $(60 \mu \mathrm{g})$ were separated and bloted onto PVDF membranes. To block non-specific binding, the PVDF membranes were subsequently blocked in Tris-buffered saline with Tween-20 (TBST) containing 5\% defatted milk buffer for $1 \mathrm{~h}$ at $37^{\circ} \mathrm{C}$ and were then incubated with antibodies against ERK, p-ERK, MMP-2, MMP-9 or $\beta$-actin overnight in defatted milk $5 \%$ in TBST at $4^{\circ} \mathrm{C}$. The membranes were incubated with a horseradish peroxidase goat anti-rabbit or anti-mouse IgG antibody at room temperature for $1 \mathrm{~h}$. The pictures were examined with an enhanced chemiluminescence kit (ECL Plus; Amersham, Freiburg, Germany) according to the manufacturer's instructions and captured by autoradiography. The relative photographic density was quantified with ImageJ software (GE Healthcare, Buckinghamshire, UK) and expressed as arbitrary units (a.u.).

Tumor xenograft experiments and animals. To assess the anti-proliferation of baicalein in vivo, Balb/c athymic nude mice (4- to 6-week-old) were obtained from Shanghai SLAC Laboratory Animal, Co., Ltd., (Shanghai, China). Each mouse was subcutenously implanted with $1 \times 10^{6}$ viable DLD1 cells in the right flank area. One group was treated with vehicle dimethyl sulfoxide (DMSO), the other group was treated with baicalein $(20 \mathrm{mg} / \mathrm{kg} / \mathrm{day})$ for 3 weeks. At day 21 , all the mice were sacrificed and the tumor tissues were removed and weighed. The experimental protocols used herein were evaluated and approved by the Animal Care and Use Committee of the Medical School of Xi'an Jiaotong University.

\section{Results}

Baicalein inhibits the proliferation of HT29 and DLDI cells. The inhibition effects of baicalein on the proliferation of CRC cells at different concentrations (0 to $120 \mu \mathrm{M}$ ) for $24 \mathrm{~h}$ are shown in Fig. 1B. At concentrations $>40 \mu \mathrm{M}$, the anti-proliferation effect of baicalein on HT29 and DLD1 cells was significant so we chose concentrations $<40 \mu \mathrm{M}$ for all the following experiments.

To determine the effect of baicalein on apoptosis in detail, HT29 cells were incubated for $48 \mathrm{~h}$ with baicalein $(40,60$ or $80 \mu \mathrm{M})$ and then analysed by flow cytometry. As shown in Fig. 1C, the effect of baicalein on apoptosis of HT29 cells was concentration-dependent. After treatment for $48 \mathrm{~h}$, both early and late apoptotic cells increased significantly in the HT29 cells treated with baicalein. Baicalein reduced the number of colony HT29 cells in vitro significantly (Fig. 1D).

Baicalein inhibits the metastasis of HT29 and DLDI cells. Fig. 2 shows the inhibition effect of baicalein $(0,10,20$ and $30 \mu \mathrm{M})$ on cell migration $(16 \mathrm{~h})$ and invasion $(24 \mathrm{~h})$ in HT29 and DLD1 cells, respectively. We found that inhibition effect of baicalein on the migration (Fig. 2A and B) and invasion (Fig. 2C and D) of HT29 and DLD1 cells was concentrationdependent.

Baicalein inhibits the expression of MMP-2/-9. We analysed the effect of baicalein on the expression of MMP-2/-9 in HT29 and DLD1 at various concentrations. Cells were treated with baicalein $(0,10,20$ and $30 \mu \mathrm{M})$ for $24 \mathrm{~h}$ and then analysed by western blotting. Fig. 3A and B show the inhibited effect of baicalein on the expression of MMP-2/-9 in HT-29 cells. The effect is concentration-dependent. Fig. $3 \mathrm{C}$ and $\mathrm{D}$ show the effect of baicalein on the expression of MMP-2/-9 in DLD1 cells.

The ERK signaling pathway is involved in the antimetastatic mechanism of baicalein in CRC. ERK signaling pathway plays an vital role in the metastasis of cancer cells by regulating MMP-2/-9 (3); hence, we detected the impact of baicalein on the activity of ERK signaling pathway in CRC cells. The results of the western blotting showed that baicalein reduced the phosphorylation level of ERK1/2 in DLD1 cells treated with baicalein (Fig. 4A and B). To further check the role of ERK signaling pathway in the antimetastatic effect of baicalein, we upregulated the activity of ERK singnaling pathway in DLD1 cells via transfecting the plasmid [pcDNA3.1 (+)-MEK1] expressing human MEK1 and found that the anti-invasion effect of baicalein was reversed by the high expression of MEK1 (Fig. 4C). The positive clones were selected by G418. DLD1 cells were 
A<smiles>O=c1cc(-c2ccccc2)oc2cc(O)c(O)c(O)c12</smiles>

B

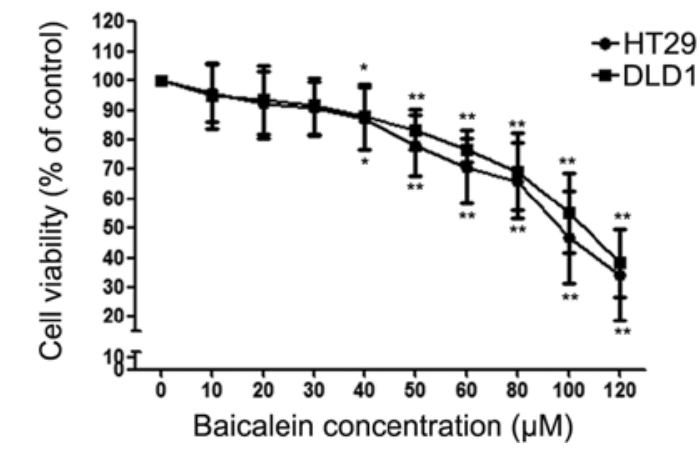

C

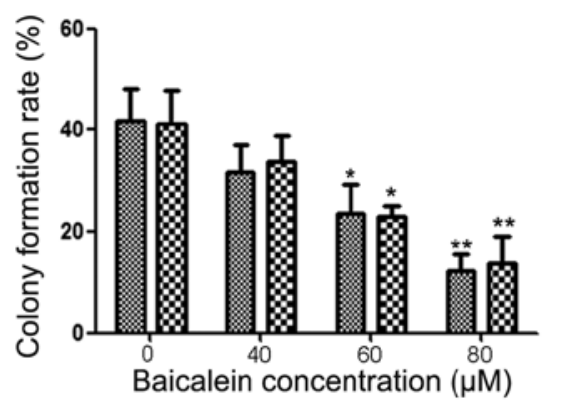

HT29

$\otimes \mathrm{DLD} 1$

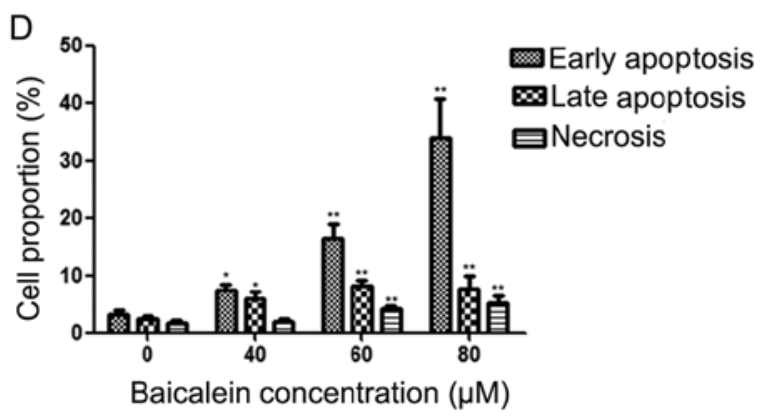

Figure 1. Chemical structure of baicalein and the anti-proliferation effect of baicalein. (A) Chemical structure of baicalein. (B) The cell viability was measured by MTT assay. (C) Baicalein inhibited the colony formation ability of CRC cells. (D) Baicalein induced the apoptosis of CRC cells. Values are represented as means \pm standard deviation (SD) of three independent experiments performed in triplicate. ${ }^{*} \mathrm{P}<0.05$ and ${ }^{* *} \mathrm{P}<0.01$ compared with the control group, respectively.

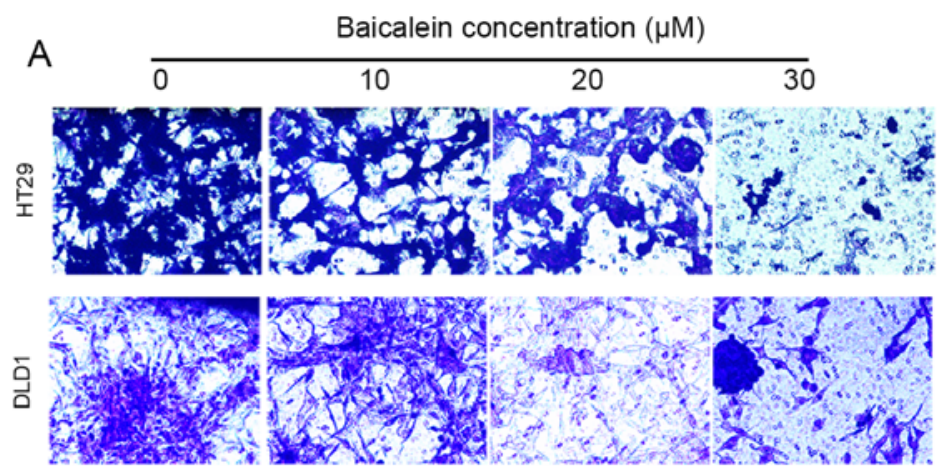

B
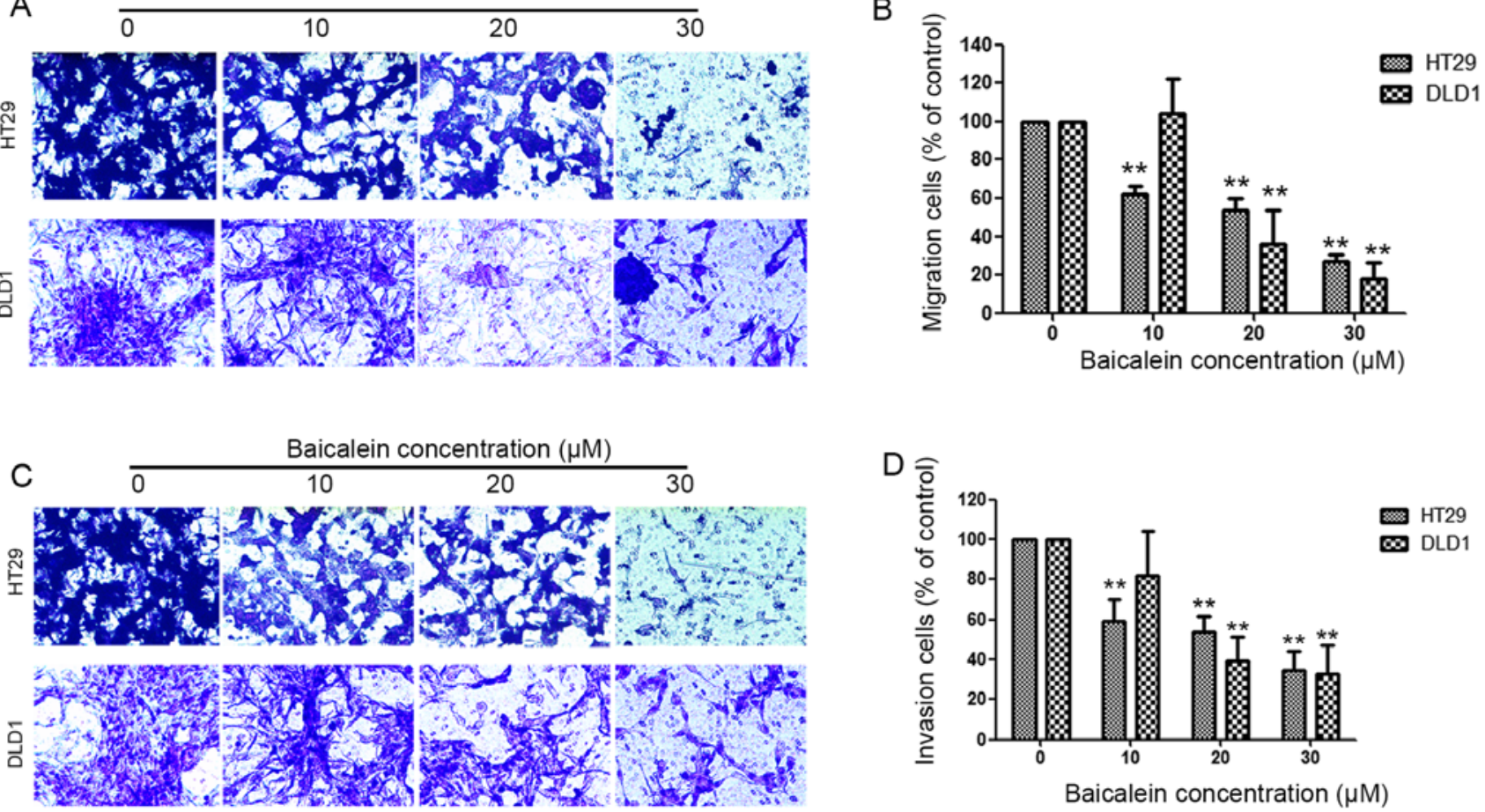

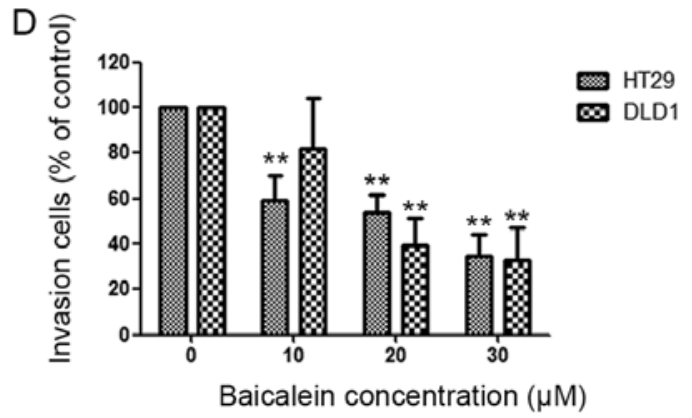

Figure 2. Baicalein inhibits the migration and invasion of CRC cells. (A) HT29 and DLD1 cells were pretreated with 0, 10,20 and $30 \mu \mathrm{M}$ baicalein for $24 \mathrm{~h}$. Then seeded onto the upper wells, FBS (10\%) was added to the bottom chambers for $16 \mathrm{~h}$ to induce cell migration. After $16 \mathrm{~h}$, cells on the bottom side of the filter were fixed, stained and counted. (B) The percentage of migration rate was expressed as a percentage of control (0 $\mu \mathrm{M})$. (C) HT29 and DLD1 cells were pretreated with $0,10,20$ and $30 \mu \mathrm{M}$ baicalein for $24 \mathrm{~h}$. Then seeded onto the upper wells, FBS (10\%) was added to the bottom chambers for $24 \mathrm{~h}$ to induce cell invasion. After $24 \mathrm{~h}$, cells on the bottom side of the filter were fixed, stained and counted. (D) The percentage of invasive rate was expressed as a percentage of control $(0 \mu \mathrm{M})$. Values are presented as means $\pm \mathrm{SD}$ of three independent experiments performed in triplicate. ${ }^{* *} \mathrm{P}<0.01$ compared with the control group, respectively.

separated into 3 groups: no treatment as the control group ' $\mathrm{C}$ ', transfected with an empty vector pcDNA3.1(+) as the negative control group ' $\mathrm{N}$ ', transfected with a pcDNA3.1(+)MEK1 as the positive group ' $M$ '. 
A

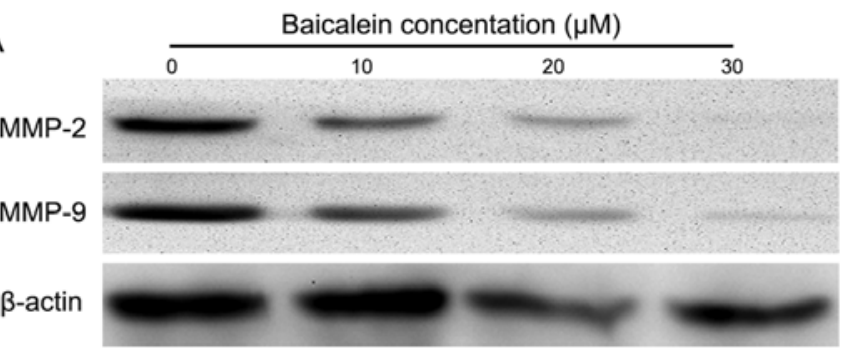

C

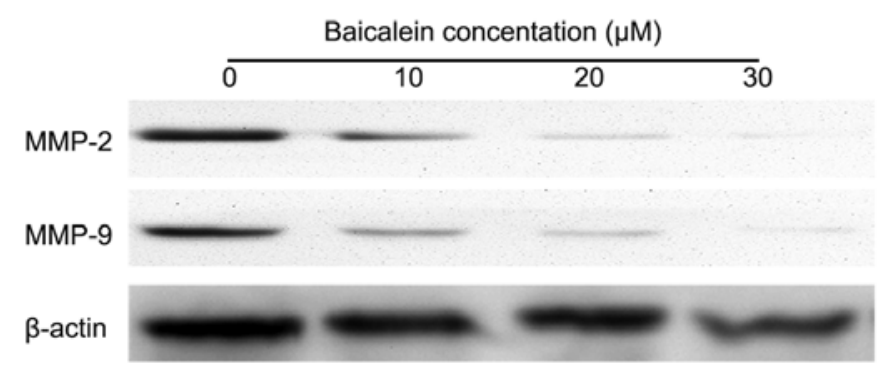

B
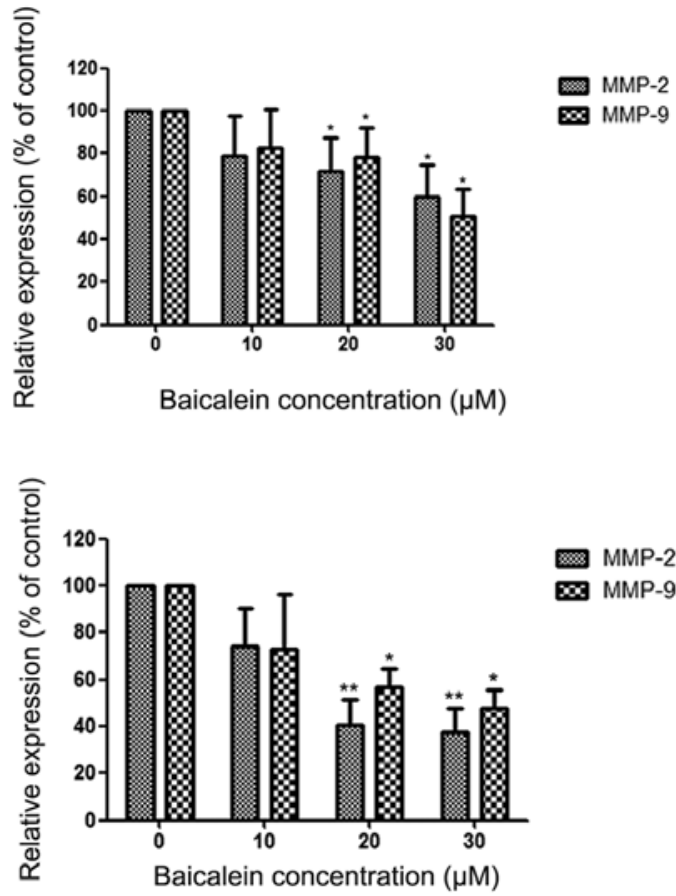

Figure 3. Baicalein suppresses the expression of MMP-2/-9 in HT29 and DLD1 cells. (A) HT29 cells were treated with baicalein $(0,10,20$ and $30 \mu \mathrm{M})$ for $24 \mathrm{~h}$ and then subjected to western blotting to analyze the protein levels of MMP-2/-9. (B) Quantification of the protein levels of MMP-2/-9 in HT29. (C) DLD1 cells were treated with baicalein $(0,10,20$ and $30 \mu \mathrm{M})$ for $24 \mathrm{~h}$ and then subjected to western blotting to analyze the protein levels of MMP-2/-9. (D) Quantification of the protein levels of MMP-2/-9 in DLD1. Values are presented as means \pm SD of three independent experiments performed in triplicate. ${ }^{*} \mathrm{P}<0.05$ and ${ }^{* * *} \mathrm{P}<0.01$ compared with the control group, respectively.
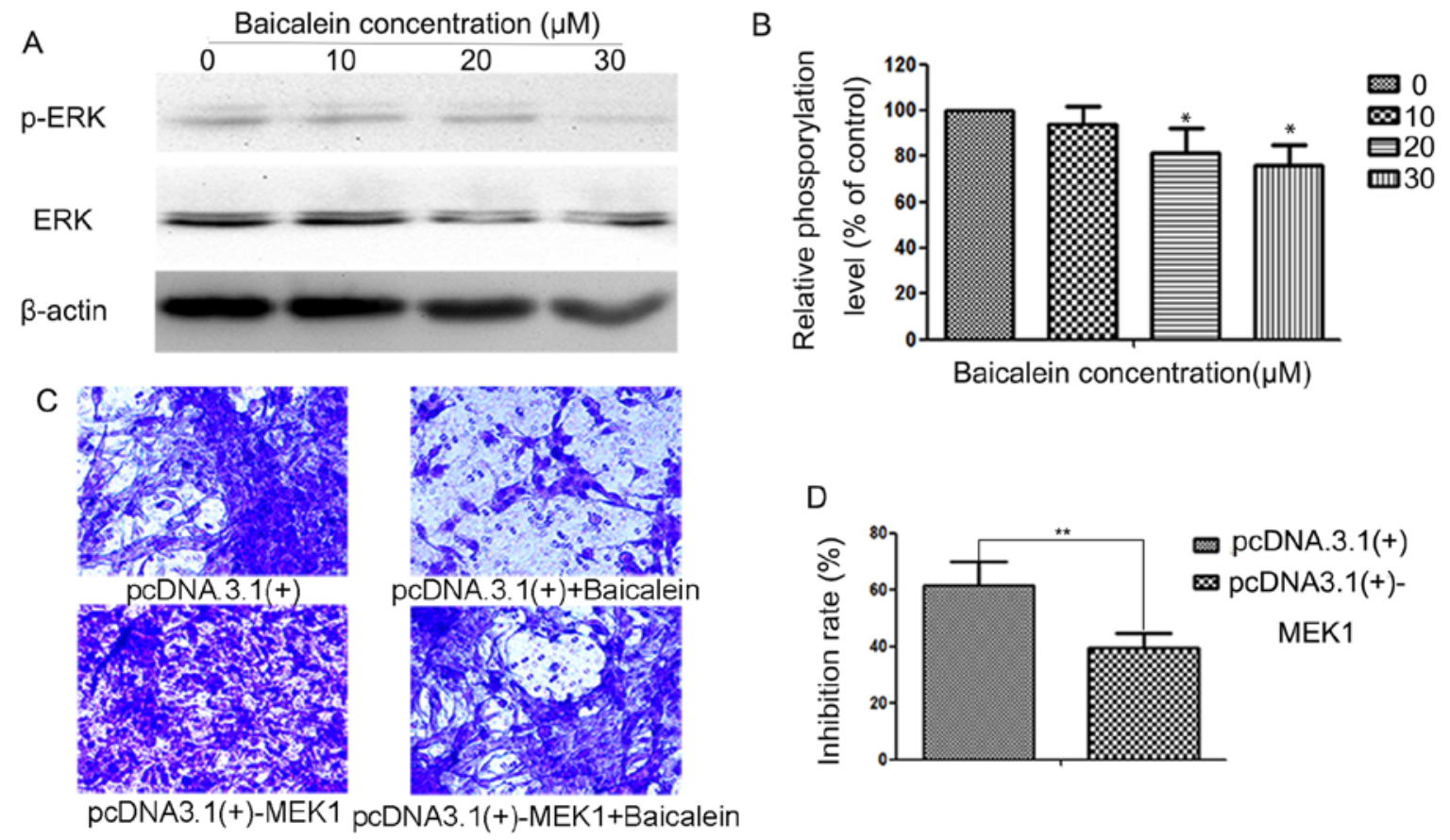

Figure 4. Effect of baicalein on ERK signaling pathway. (A) The protein levels of ERK and p-ERK. (B) Phosphorylation densities of ERK were digitally scanned. (C) Transwell assays were executed to evaluate anti-metastatic effects of baicalein on two groups of cells ['pcDNA3.1 (+)', the group transfected with an empty vector pcDNA3.1 (+), 'pcDNA3.1 (+)-MEK1', the group transfected with a pcDNA3.1 (+)-MEK1]. (D) The inhibition rates of baicalein on two groups of cells [transfected with an empty vector pcDNA3.1 (+), transfected with a pcDNA3.1 (+)-MEK1]. Values are presented as means \pm SD of three independent experiments performed in triplicate. ${ }^{*} \mathrm{P}<0.05$ and ${ }^{* *} \mathrm{P}<0.01$ compared with the control group, respectively.

The inhibition rate was $\sim 61.3$ and $39.3 \%$ after $24 \mathrm{~h}$ of treatment with 0 or $30 \mu \mathrm{M}$ of baicalein (Fig. 4D). Baicalein could also inhibit the phosphorylation level of ERK in the
HT29 cells (data not shown). Our results also show that the combined treatment with the baicalein and U0126 (an ERK inhibitor) reduced both the MMP-2/-9 protein expres- 
A

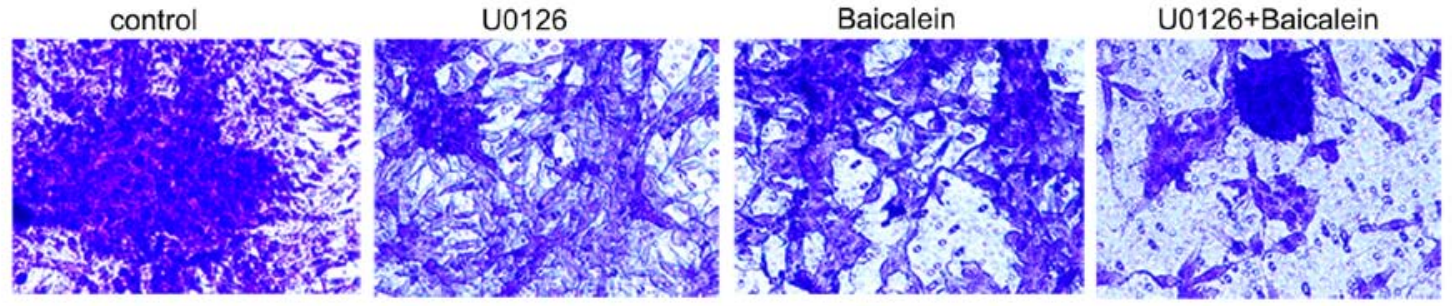

B
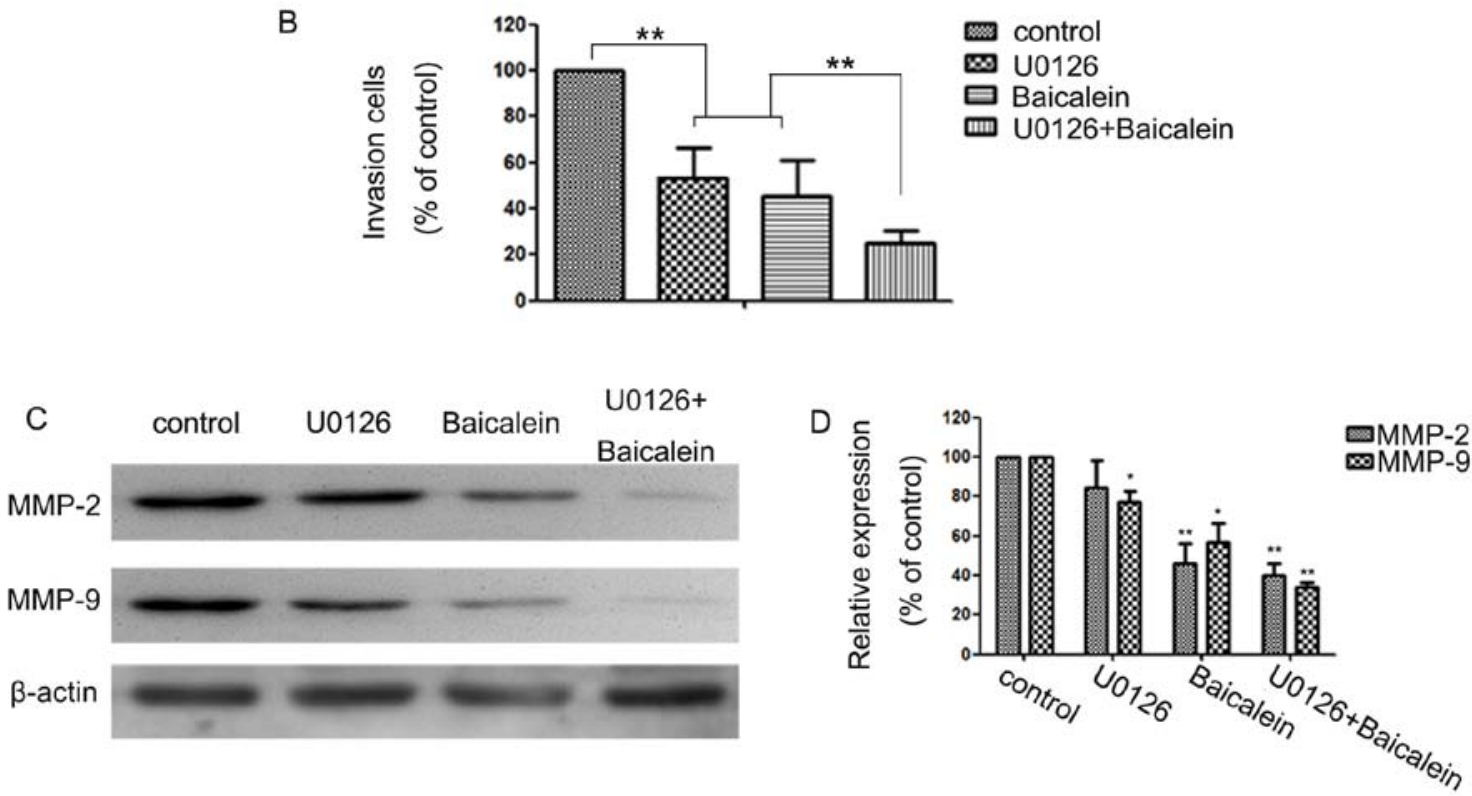

Figure 5. Effects of ERK inhibitor (U0126) and baicalein on cell invasion and MMP-2/-9 of DLD1 cells. (A) Cells were pretreated with U0126 (10 $\mu \mathrm{M})$ for $30 \mathrm{~min}$, then incubated in the presence or absence of baicalein $(20 \mu \mathrm{M})$ for $24 \mathrm{~h}$. The cell invasive abilities were performed by Boyden chamber invasion assay. (B) The percentage of invasive rate was expressed as a percentage of control. (C and D) DLD1 cells were treated and then subjected to western blotting to analyze the protein levels of MMP-2/-9. Values are presented as means \pm SD of three independent experiments performed in triplicate. ${ }^{*} \mathrm{P}<0.05$ and ${ }^{* *} \mathrm{P}<0.01$ compared with the control group, respectively.

sion (Fig. 5A and B) and the cell invasion significantly (Fig. 5C and D).

Baicalein inhibits the growth of CRC tumors in vivo. The inhibition effect of baicalein on DLD1 xenograft growth is shown in Fig. 6A. We found that baicalein could inhibit CRC growth significantly. At day 21, all the mice were sacrificed and the tumor tissues were removed and weighed. Compared to the control group, baicalein reduced the volume of solid tumors significantly (Fig. 6B). We also found that baicalein significantly inhibited phosphorylation level of ERK and the expression of MMP-2/-9 in vivo. The inhibition effect of baicalein on the phosphorylation level of ERK is shown in Fig. 6C and $\mathrm{D}$, and on expression of MMP-2/-9 is shown Fig. $6 \mathrm{E}$ and $\mathrm{F}$ in vivo.

\section{Discussion}

Baicalein possesses antitumor effect in many tumors (17-19), but the reports on baicalein effect are rare in CRC. We found that baicalein significantly inhibited the migration and invasion of CRC cells by inhibiting MMP-2/-9 expression via inhibiting the ERK signaling pathway.

Our results showed that baicalein inhibited the proliferation and colony formation ability of CRC cells and the mechanism is correlated with apoptosis. Transwell chamber is generally used as an assay to detect the metastasis ability of cancer cells. In the study, we chose the concentration below cytotoxicity to detect the effect of baicalein on the migration of CRC cells. We found that baicalein could inhibit the migration and invasion ability of CRC cells. Our finding is similar to previous research in other cancers $(3,11,15,16)$, in which baicalein could inhibit the proliferation of hepatocellar carcinoma cells, glioma and breast cancer cells. As concentrations are below the cytotoxicity concentration, the inhibition effect is not correlated with the cytotoxicity of baicalein. To the best of our knowledge, we first show the effect of baicalein on DLD1 CRC cells whicn was used for research on proliferation, apoptosis and invasion of CRC (20-22). The inhibitory properties are probably related to the specific structural features of baicalein (as shown in Fig. 1A). It was reported that the hydroxylation of C5 and C7 in A-ring significantly improved the anticancer activity of flavonoids over that of 5-fluorouracil (23). Moreover, it has been demonstrated that the hydroxyl substitutions in the A-ring (C7) of baicalein are crucial for its anti-metastatic effects against human hematoma cells (24).

To date, metastasis of CRC causes thousands of deaths every year worldwide (25). Degradation of the ECM of lymph or blood vessels excert important roles in the metastasis of 

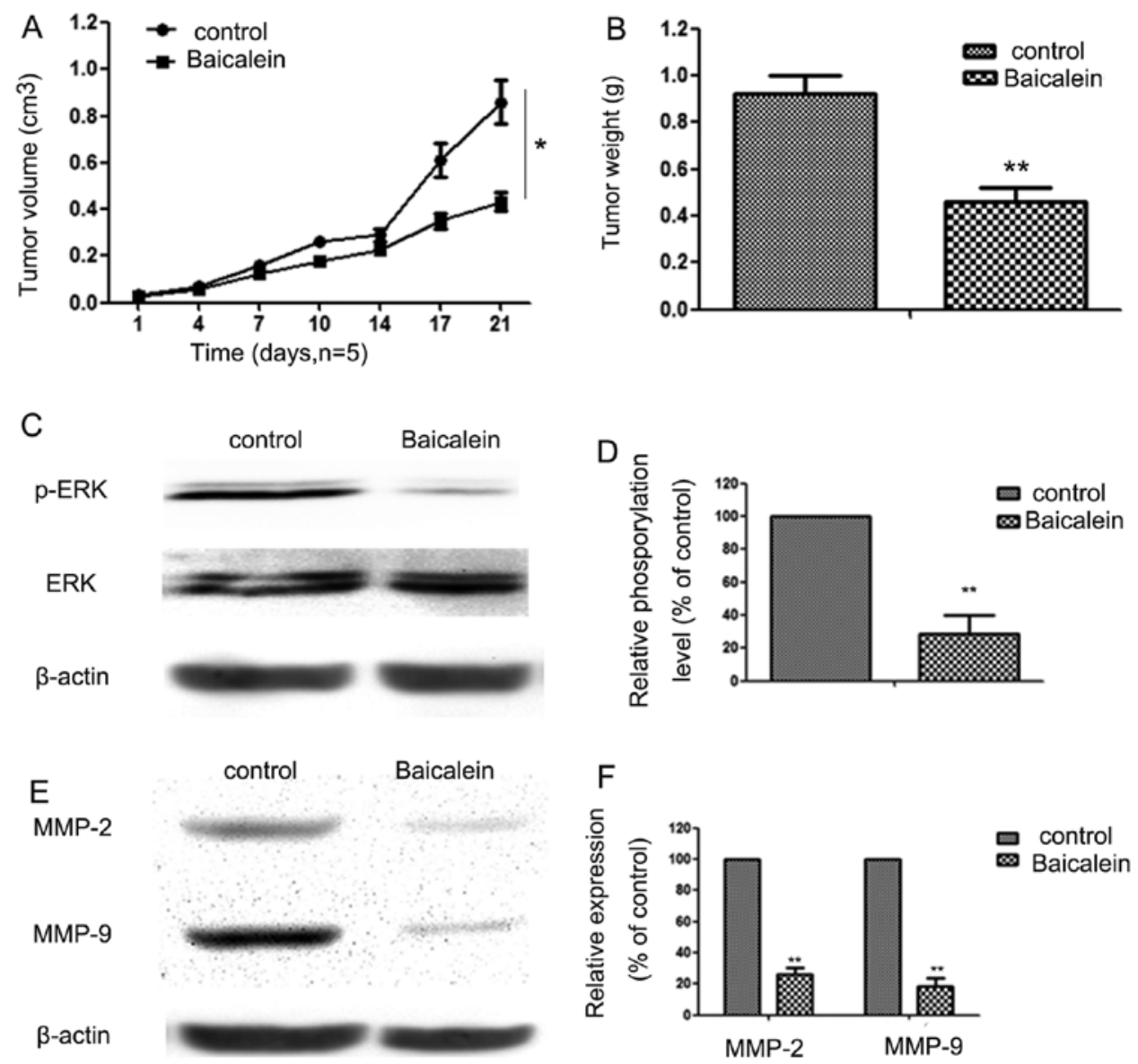

Figure 6. The anti-metastasis effects of baicalein on CRC in vivo. To evaluate the in vivo effects of baicalein on tumor growth, DLD1 cells were xenografted into nude mice as previously described. The time course of DLD1 xenograft growth with and without baicalein treatment is shown in (A). By evaluating the xenograft tumor volume, a significant inhibition of tumor growth by baicalein was observed. In the baicalein-treated $(20 \mathrm{mg} / \mathrm{kg} / \mathrm{day}) \mathrm{mice}$ at $21 \mathrm{days}$ after cell implantation, the DLD1 xenograft volumes were inhibited significantly compared to control group. At the end of the experiment, the xenograft tumors were removed and weighed. Baicalein significantly decreased the solid tumor mass compared to the control group (B). Baicalein significantly inhibits the phosphorylation level of ERK in DLD1 cell xenograft tumors (C and D). Baicalein significantly suppresses the expression of MMP-2/-9 in DLD1 cell xenograft tumors $(\mathrm{E}$ and $\mathrm{F}) .{ }^{* *} \mathrm{P}<0.01$ compared with the control group.

cancers via allowing the invasion of cancer cells into the circulation system and invade distant organs or tissues (26). MMPs, especially MMP-2/-9, play important roles in degrading ECM (27). Baicalein shows inhibition effect on the expression of MMP-2/-9 in hepatocellular carcinoma and glioma $(3,16)$. Our results showed the inhibition effect of baicalein on MMP-2/-9 expression in CRC cells. The results suggest that MMP-2/-9 play important roles in the anti-metastatic effect of baicalein in CRC cells.

Multiple signaling cascades play important roles in the synthesis of MMPs, especially the ERK signaling pathway $(19,28,29)$. ERK signaling pathway plays an important role in tumor invasion via promoting the degradation of ECM proteins $(30,31)$. Studies have shown that the inhibition of ERK phosphorylation reduces the expression of MMP-2/-9 in the CRC cells $(32,33)$. To investigate the related mechanism(s) of the inhibition effect of baicalein on CRC metastasis, we detected the activity of ERK signaling pathway in CRC cells. The results proved that baicalein reduced the activity of ERK signaling pathway significantly. Upregulation of ERK signaling pathway activity abolished the baicalein's antimetastatic effect. The results was similar to a previous study, in which baicalein inhibited the expres- sion and activity of MMP-2 and MMP-9 via inhibiting the activity of ERK signaling pathway (3).

Our results also showed that combined treatment with baicalein and U0126 (an ERK inhibitor) reduced both the MMP-2/-9 protein expression (Fig. 5A and B) and the cell invasion significantly (Fig. 5C and D) suggesting that baicalein directly downregulated the ERK signaling pathway, which were similar to previous studies conducted in other types of carcinomas (3). Finally, our results demonstrated that baicalein can inhibit the growth of CRC xenografts in vivo.

In conclusion, the present study demonstrated the antimetastatic effect of baicalein on CRC. Furthermore, ERK signaling pathway plays a vitally important role in the antimetastatic effect of baicalein on CRC cells by regulating MMP-2/-9. These findings revealed that baicalein may represent a new potential anti-metastatic therapy for CRC.

\section{References}

1. Ma YS, Hsiao YP, Lin JH, Hsu SC, Chueh FS, Weng SW, Lai KC, Lin JG and Chung JG: Crude extract of Rheum palmatum L inhibits migration and invasion of LS1034 human colon cancer cells acts through the inhibition of matrix metalloproteinase-2/-9 by MAPK signaling. Environ Toxicol 30: 852-863, 2014. 
2. Patiutko IuI, Pylev AL, Sagădak IV, Poliakov AN, Chuchuev ES Abgarian MG and Shishkina NA: Surgical and combined treatment of patients with metastatic liver and lymph nodes invasion by colorectal cancer. Khirurgiia (Mosk) 7: 49-54, 2010 (In Russian).

3. Chen K, Zhang S, Ji Y, Li J, An P, Ren H, Liang R, Yang J and Li Z: Baicalein inhibits the invasion and metastatic capabilities of hepatocellular carcinoma cells via down-regulation of the ERK pathway. PLoS One 8: e72927, 2013.

4. Gialeli C, Theocharis AD and Karamanos NK: Roles of matrix metalloproteinases in cancer progression and their pharmacological targeting. FEBS J 278: 16-27, 2011.

5. Hoshino R, Chatani Y, Yamori T, Tsuruo T, Oka H, Yoshida O, Shimada Y, Ari-i S, Wada H, Fujimoto J, et al: Constitutive activation of the 41-/43-kDa mitogen-activated protein kinase signaling pathway in human tumors. Oncogene 18: 813-822, 1999.

6. Zhang H, Shen B, Swinarska JT, Li W, Xiao K and He P: 9-Hydroxypheophorbide $\alpha$-mediated photodynamic therapy induces matrix metalloproteinase-2 (MMP-2) and MMP-9 down-regulation in Hep-2 cells via ROS-mediated suppression of the ERK pathway. Photodiagn Photodyn Ther 11: 55-62, 2014.

7. Kress TR, Raabe T and Feller SM: High Erk activity suppresses expression of the cell cycle inhibitor p27Kip1 in colorectal cancer cells. Cell Commun Signal 8: 1, 2010.

8. Park KS, Lee NG, Lee KH, Seo JT and Choi KY: The ERK pathway involves positive and negative regulations of HT-29 colorectal cancer cell growth by extracellular zinc. Am J Physiol Gastrointest Liver Physiol 285: G1181-G1188, 2003.

9. Kim HC, Kim YS, Oh HW, Kim K, Oh SS, Kim JT, Kim BY, Lee SJ, Choe YK, Kim DH, et al: Collagen triple helix repeat containing 1 (CTHRC1) acts via ERK-dependent induction of MMP9 to promote invasion of colorectal cancer cells. Oncotarget 5: 519-529, 2014

10. Ai X, Wu Y, Zhang W, Zhang Z, Jin G, Zhao J, Yu J, Lin Y, Zhang W, Liang H, et al: Targeting the ERK pathway reduces liver metastasis of Smad4-inactivated colorectal cancer. Cancer Biol Ther 14: 1059-1067, 2013

11. Wang L, Ling Y, Chen Y, Li CL, Feng F, You QD, Lu N and Guo QL: Flavonoid baicalein suppresses adhesion, migration and invasion of MDA-MB-231 human breast cancer cells. Cancer Lett 297: 42-48, 2010

12. Kim DH, Hossain MA, Kang YJ, Jang JY, Lee YJ, Im E, Yoon JH, Kim HS, Chung HY and Kim ND: Baicalein, an active component of Scutellaria baicalensis Georgi, induces apoptosis in human colon cancer cells and prevents AOM/DSS-induced colon cancer in mice. Int J Oncol 43: 1652-1658, 2013

13. Chen J, Li Z, Chen AY, Ye X, Luo H, Rankin GO and Chen YC: Inhibitory effect of baicalin and baicalein on ovarian cancer cells. Int J Mol Sci 14: 6012-6025, 2013.

14. Li HL, Zhang S, Wang Y, Liang RR, Li J, An P, Wang ZM, Yang J and Li ZF: Baicalein induces apoptosis via a mitochondrialdependent caspase activation pathway in T24 bladder cancer cells. Mol Med Rep 7: 266-270, 2013

15. Liang RR, Zhang S, Qi JA, Wang ZD, Li J, Liu PJ, Huang C, Le XF, Yang J and Li ZF: Preferential inhibition of hepatocellular carcinoma by the flavonoid Baicalein through blocking MEK-ERK signaling. Int J Oncol 41: 969-978, 2012

16. Zhang Z, Lv J, Lei X, Li S, Zhang Y, Meng L, Xue R and Li Z: Baicalein reduces the invasion of glioma cells via reducing the activity of p38 signaling pathway. PLoS One 9: e90318, 2014.

17. Chandrashekar N, Selvamani A, Subramanian R, Pandi A and Thiruvengadam D: Baicalein inhibits pulmonary carcinogenesisassociated inflammation and interferes with COX-2, MMP-2 and MMP-9 expressions in-vivo. Toxicol Appl Pharmacol 261: 10-21, 2012.

18. Wu B, Li J, Huang D, Wang W, Chen Y, Liao Y, Tang X, Xie H and Tang F: Baicalein mediates inhibition of migration and invasiveness of skin carcinoma through Ezrin in A431 cells. BMC Cancer 11: 527, 2011
19. Wang ZD, Huang C, Li ZF, Yang J, Li BH, Liang RR, Dai ZJ and Liu ZW: Chrysanthemum indicum ethanolic extract inhibits invasion of hepatocellular carcinoma via regulation of MMP/ TIMP balance as therapeutic target. Oncol Rep 23: 413-421, 2010.

20. Organ SL, Hai J, Radulovich N, Marshall CB, Leung L, Sasazuki T, Shirasawa S, Zhu CQ, Navab R, Ikura M, et al: p120RasGAP is a mediator of rho pathway activation and tumorigenicity in the DLD1 colorectal cancer cell line. PLoS One 9: e86103, 2014.

21. Laezza C, Caruso MG, Gentile T, Notarnicola M, Malfitano AM, Di Matola T, Messa C, Gazzerro P and Bifulco M: N6-isopentenyladenosine inhibits cell proliferation and induces apoptosis in a human colon cancer cell line DLD1. Int J Cancer 124: 1322-1329, 2009

22. Shida D, Kitayama J, Yamaguchi H, Okaji Y, Tsuno NH, Watanabe T, Takuwa $\mathrm{Y}$ and Nagawa H: Lysophosphatidic acid (LPA) enhances the metastatic potential of human colon carcinoma DLD1 cells through LPA1. Cancer Res 63: 1706-1711, 2003.

23. Ibrahim A, Sobeh M, Ismail A, Alaa A, Sheashaa H, Sobh M and Badria F: Free-B-Ring flavonoids as potential lead compounds for colon cancer therapy. Mol Clin Oncol 2: 581-585, 2014.

24. Chiu YW, Lin TH, Huang WS, Teng CY, Liou YS, Kuo WH, Lin WL, Huang HI, Tung JN, Huang CY, et al: Baicalein inhibits the migration and invasive properties of human hepatoma cells. Toxicol Appl Pharmacol 255: 316-326, 2011.

25. Dziki L, Przybyłowska K, Majsterek I, Trzciński R, Mik M and Sygut A: A/G polymorphism of the MMP-7 gene promoter region in colorectal cancer. Pol Przegl Chir 83: 622-626, 2011.

26. Artym VV, Yamada KM and Mueller SC: ECM degradation assays for analyzing local cell invasion. Methods Mol Biol 522: 211-219, 2009.

27. Zhang Y, Liu H, Jin J, Zhu X, Lu L and Jiang H: The role of endogenous reactive oxygen species in oxymatrine-induced caspase-3-dependent apoptosis in human melanoma A375 cells. Anticancer Drugs 21: 494-501, 2010.

28. Cohen M, Meisser A, Haenggeli L and Bischof P: Involvement of MAPK pathway in TNF-alpha-induced MMP-9 expression in human trophoblastic cells. Mol Hum Reprod 12: 225-232, 2006.

29. Liu SQ, Huang JA, Qin MB, Su YJ, Lai MY, Jiang HX and Tang GD: Sphingosine kinase 1 enhances colon cancer cell proliferation and invasion by upregulating the production of MMP-2/9 and uPA via MAPK pathways. Int J Colorectal Dis 27: 1569-1578, 2012

30. Chen YY, Liu FC, Chou PY, Chien YC, Chang WS, Huang GJ, $\mathrm{Wu} \mathrm{CH}$ and Sheu MJ: Ethanol extracts of fruiting bodies of Antrodia cinnamomea suppress CL1-5 human lung adenocarcinoma cells migration by inhibiting matrix metalloproteinase-2/9 through ERK, JNK, p38, and PI3K/Akt signaling pathways. Evid Based Complement Alternat Med 2012: 378415, 2012.

31. Lin F, Chengyao X, Qingchang L, Qianze D, Enhua W and Yan W: CRKL promotes lung cancer cell invasion through ERK-MMP9 pathway. Mol Carcinog 54 (Suppl 1): E35-E44, 2014.

32. Deng W, Sui H, Wang Q, He N, Duan C, Han L, Li Q, Lu M, and Lv S: A Chinese herbal formula, Yi-Qi-Fu-Sheng, inhibits migration/invasion of colorectal cancer by down-regulating MMP-2/9 via inhibiting the activation of ERK/MAPK signaling pathways. BMC Complement Altern Med 13: 65, 2013.

33. Babykutty S, Suboj P, Srinivas P, Nair AS, Chandramohan K and Gopala S: Insidious role of nitric oxide in migration/invasion of colon cancer cells by upregulating MMP-2/9 via activation of cGMP-PKG-ERK signaling pathways. Clin Exp Metastasis 29: 471-492, 2012. 